\title{
Investigating the Magnetic Characteristics of 12/8 Switched Reluctance Motor for Enhanced Starting Torque
}

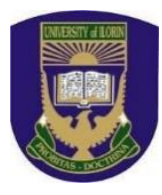

\author{
E. C. Abunike', G. D. Umoh'², I. E. Nkan³, O. I. Okoro ${ }^{1}$ \\ ${ }^{1}$ Department of Electrical and Electronic Engineering, Michael Okpara University of Agriculture, \\ Umudike, Nigeria. \\ ${ }^{2}$ Department of Electrical and Electronic Engineering, Maritime Academy of Nigeria, Oron, Nigeria. \\ ${ }^{3}$ Department of Electrical and Electronic Engineering, AkwaIbom State University, MkpatEnin, Nigeria.
}

ABSTRACT: The switched reluctance motor (SRM) is among the special purpose electric machine family. It is simple in construction and avoids use of magnet so it is cheap to manufacture. The magnetic characteristics and simulation of three phase 12/8 switched reluctance motor (SRM) for enhanced starting torque is presented. The motor was analyzed using finite element technique (FET) and it was improved by focusing on the impact of important geometrical parameters on torque and efficiency. From the simulated results, the motor attained maximum efficiency of $91.7 \%$ at a speed of $1648.6 \mathrm{rpm}$ and recorded a maximum torque of $321.1 \mathrm{Nm}$ at a speed of $34.4 \mathrm{rpm}$. The magnetic flux lines and densities were also recorded. The maximum and minimum magnetic flux lines of the motor as observed were $1.2 \times 10^{-3} \mathrm{~Wb} / \mathrm{m}$ and $-8.5 \times 10^{-4} \mathrm{~Wb} / \mathrm{m}$ respectively while the respective values of the maximum and minimum magnetic flux density of the motor were $3.8 \times 10^{-1} \mathrm{~T}$ and $2.11 \times 10^{-9} \mathrm{~T}$. The results show that most of the field energy is confined within the motor and also concentrated in the air gap region of the motor. Dynamic analysis of the motor was performed for $0.02 \mathrm{~s}$ at a damping coefficient of $0.71 \mu \mathrm{Nms} / \mathrm{rad}$. The results showed that the motor has lower torque ripple. The preference to use this type of motor where high speed operation and better starting torque are needed has been highlighted in this study.

KEYWORDS: Switched reluctance motor, static characteristics, transient analysis, torque, magnetic flux

[Received May 10, 2020, Revised Nov. 18, 2020, Accepted Feb. 01, 2021]

Print ISSN: 0189-9546 | Online ISSN: 2437-2110

\section{INTRODUCTION}

The SRM has been actively researched for over a decade with very promising results which make them good candidate for industrial applications (Hams et al, 2004, Jisha et al, 2015, Sagar et al, 2014, and Yusuf, 2010). The SRM has a good overall performance over a wide range of torque-speed due to its simple and rugged constructional features. Recently, doubly-salient SRMs have been found to be a substitute in variable speed drives and generating systems and they are utilized as drive systems in electric vehicles (Wang and Feng, 2018). These machines are of simple design, high start-up torque and low inertia torque with high maximum speed and high reliability with speed that can be controlled in a wide range of operation (Krishnan, 2001, Miller, 2001, and Piotr et al, 2006).

Electric vehicles have gotten the attention of the automotive industry due to increased global research into reducing the use of fossil fuels and, as a result, lowering carbon dioxide emissions. These concerns have prompted the automotive industries to conduct research in order to develop a green and fuel-efficient vehicle technology. Brushless DC machines are the majority of machines used in electric vehicles due to their high power density and reliability (Lin et al, 2015). However, when it comes to the cost of the machine, the rare earth magnets used in the machines, which are the primary reason for achieving high power density create uncertainty; hence the conventional machines are not suitable for EV applications. Since there is no demagnetization in the switched reluctance motor (SRM) configuration, which is necessary in EV applications, more attention is being paid to SRM in order to meet the demand of automotive industry (Desai et al, 2010).

This motor has advantages like; fewer materials are needed in its construction; greater manufacturing economy; they offer higher power density for higher speeds (Krishnan, 2001). However, the motor has some disadvantages such as: requirement of its own drive circuit as the SRM cannot utilize the circuit used by other AC machines; faster wear and tear of the bearings which can occur if there is an uneven air gap leading to rotor eccentricities (Simone, 2016).

There are many possible topological structures for SRM based on the number of phases and the number of poles of stator and rotor. For example; 3-phase 6/4 poles SRM, 3-phase 12/8 poles SRM, 4-phase 8/6 poles SRM, etc (Son et al, 2019). A3-phase 12/8 pole SRM is used in this paper. The machine is modeled to suit high speed operation, better starting torque and lower torque ripple. The objective of this work is to simulate a 12/8 SRM for enhanced starting torque and investigate the magnetic characteristics. Finite element technique was adopted in this work. Rotating Machinery Expert (RMxprt) and 
Maxwell 2D was used for the modeling and simulation of the proposed motor respectively.

\section{MATERIALS AND METHODS}

\section{A. Equivalent circuit of SRM}

SRM has certain novel features; the stator has windings but the rotor does not have coils or magnets. SRMs are often referred to as a doubly salient motor because the stator and rotor have salient poles (Mecrowet al, 2002; Oyamaet al, 2004 and Oyamaet al, 2005). Figure 1 is the motor geometry of the 12/8 SRM adopted in this study.

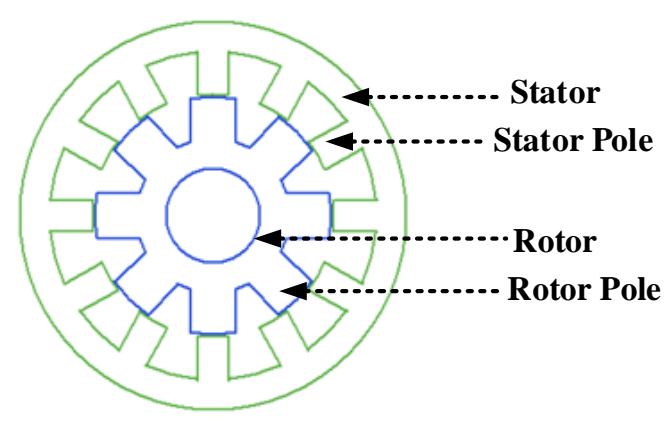

Figure 1: Geometry of 12/8 SRM (ANSYS Inc., 2018).

The injecting of currents into the stator windings whenever there is a variation of reluctance will lead to the production of torque and power as a result of the movement of the rotor. This variable speed motor is known as a switched reluctance motor (Krishnan, 2001, Nirdesh, 2018, and Vijay et al, 2012). Figure 2 is the electrical equivalent circuit of SRM which can be derived neglecting the mutual inductance between the phases.

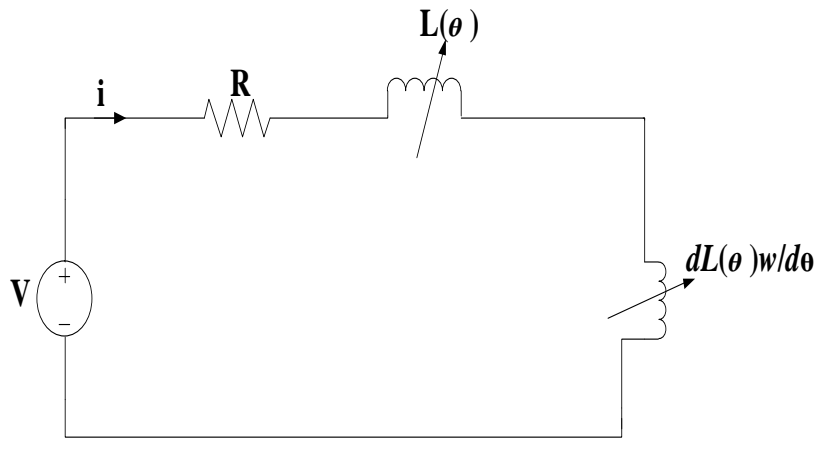

Figure 2: Equivalent circuit of SRM (Kakilli, 2011).

The voltage per phase equation of SRM is:

$$
V=R i+\frac{d \lambda(\theta, i)}{d t}
$$

where; $V=$ voltage source; $R=$ resistance of the stator winding; = flux linkage per phase given by:

$$
\lambda=L(\theta, i) i
$$

where $L$ is the inductance dependent on the rotor position and phase current.

Putting Eq. (2) in Eq. (1) yields Eq. (3);

$$
\begin{gathered}
V=R i+\frac{d\{L(\theta, i) i\}}{d t} \\
V=R i+L(\theta, i) \frac{d i}{d t}+i \frac{d \theta}{d t} \cdot \frac{d L(\theta, i)}{d \theta} \\
V=R i+\frac{L(\theta, i) d i}{d t}+\frac{d L(\theta, i)}{d \theta} \omega_{m} i
\end{gathered}
$$

In Eq. (5), the three terms on the right-hand side represent the resistive voltage drop, inductive voltage drop, and induced emf, respectively (Krishnan, 2001).

\section{B. Methods}

The accurate sizing of the motor was done by using RMxprt, after which the model was exported to Maxwell 2D environment for a detained analysis. The parameters of the base design of (Ahmad, 2017) have been modified by carefully focusing on the impact of these parameters on torque and efficiency. The modified parameters will have great impact on the performance of the motor as a result of the new air-gap length of $0.15 \mathrm{~mm}$ used in this work. These modified parameters are presented in the $3^{\text {rd }}$ column of Table 1 and the rated voltage and speed of the proposed motor are $220 \mathrm{~V}$ and $1500 \mathrm{rpm}$ respectively. Table 1 shows the data of the proposed SRM.

Table 1: Modified geometrical parameters of SRM.

\begin{tabular}{lcc}
\hline Parameters & $\begin{array}{c}\text { Base } \\
\text { dimensions }\end{array}$ & $\begin{array}{c}\text { Modified } \\
\text { dimensions }\end{array}$ \\
\hline $\begin{array}{l}\text { Inner diameter of } \\
\text { the rotor (mm) } \\
\begin{array}{l}\text { Outer diameter of } \\
\text { the rotor (mm) }\end{array}\end{array}$ & 60 & 60 \\
$\begin{array}{l}\text { Pole number of the rotor } \\
\text { Length of rotor core } \\
\text { (mm) }\end{array}$ & 180 & 181.35 \\
$\begin{array}{l}\text { Outer diameter of } \\
\text { the stator (mm) }\end{array}$ & 100 & 8 \\
$\begin{array}{l}\text { Inner diameter of } \\
\text { the stator (mm) }\end{array}$ & 270 & 100 \\
$\begin{array}{l}\text { Pole number of } \\
\text { the stator }\end{array}$ & 182 & 268.5 \\
$\begin{array}{l}\text { Stator core length } \\
\text { (mm) }\end{array}$ & 12 & 181.5 \\
Air-gap length (mm) & 99 & 12 \\
$\begin{array}{l}\text { Winding number per } \\
\text { phase }\end{array}$ & 2 & 99 \\
Core material & 142 & 0.15 \\
\hline
\end{tabular}

Figure 3 is the winding configuration of the motor while Figure 4 is the meshed model. 


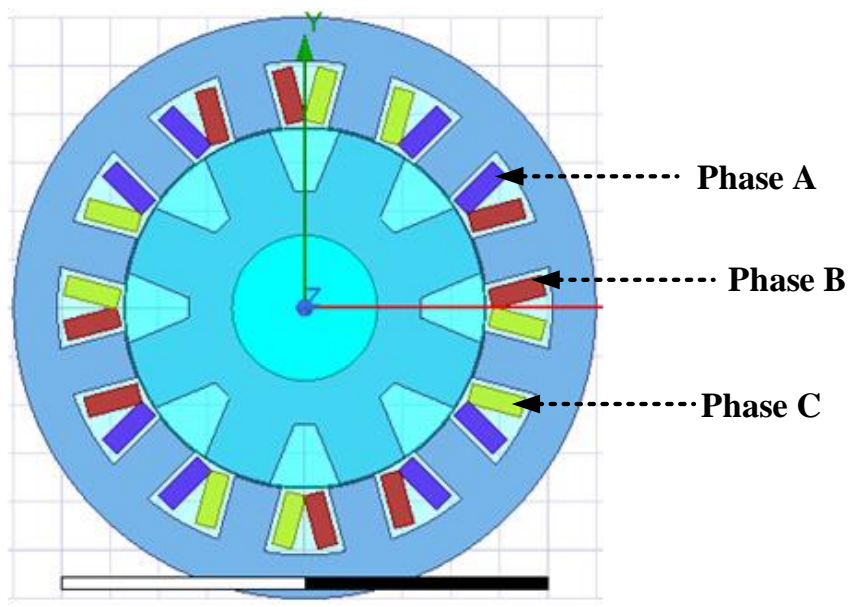

Figure 3: Winding configuration of the motor.

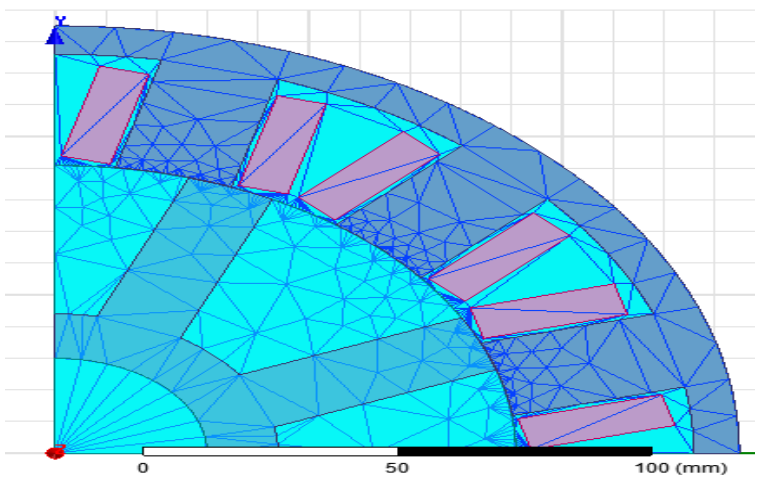

Figure 4: Meshed model (one-quarter) of the motor.

\section{RESULTS AND DISCUSSION}

\section{A. Characteristic Curves of SRM}

The basic characteristics of the motor considered in this paper are relationships between efficiency, output power, output torque and speed; flux linkages and currents at different electric degrees; efficiency and output power; flux linkages, maximum phase current and electric degree. Figures 5-7 show the relationship of efficiency, output power, and output torque of the motor as they vary with the speed.

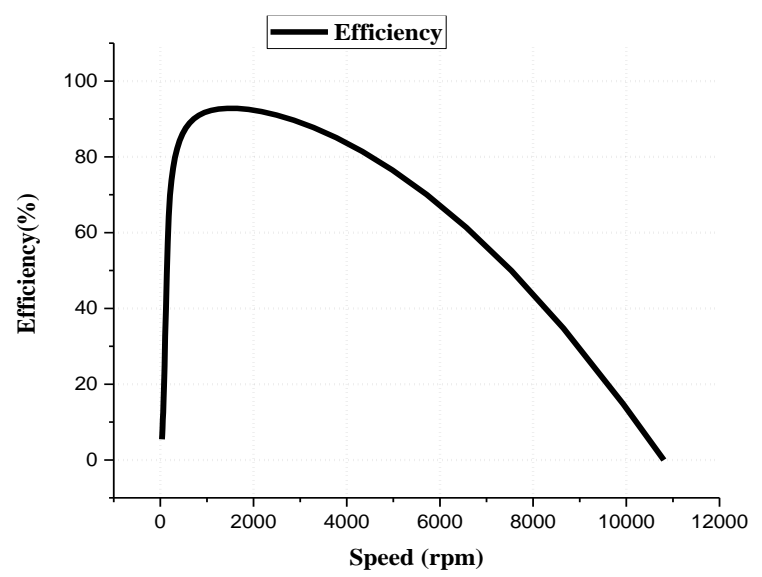

Figure 5: Variation of efficiency with speed.

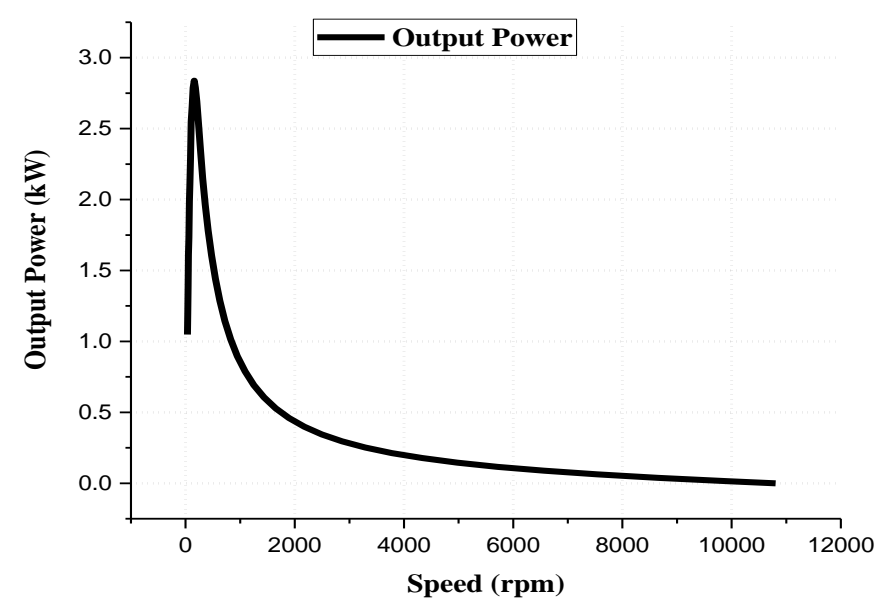

Figure 6: Variation of output power with speed.

The efficiency of the motor is $90.6 \%$ at a rated speed of $1500 \mathrm{rpm}$ as shown in Figure 5 while the motor attains maximum efficiency of $91.7 \%$ at a speed of $1648.62 \mathrm{rpm}$. It shows that 12/8 SRM can be used in high speed operation.

The motor records an output power of $2.8 \mathrm{~kW}$ when the speed is $137.13 \mathrm{rpm}$ but at the rated speed, the power becomes $0.7 \mathrm{~kW}$ as observed in Figure 6. The relationship of the output torque with speed has been presented in Figure 7.The motor recorded an efficiency of $90.7 \%$ when the output power was $0.7 \mathrm{~kW}$ as shown in Figure 8.

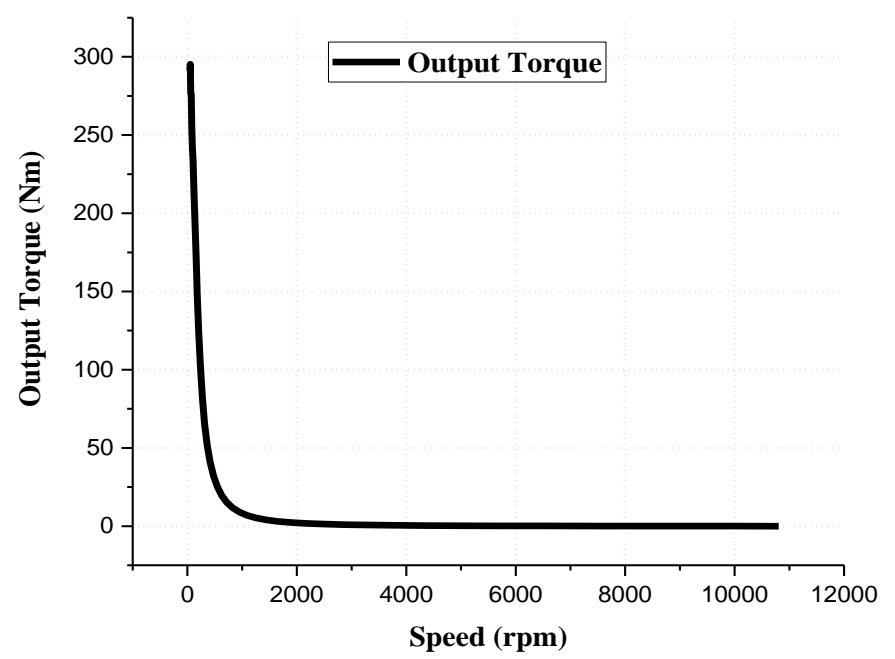

Figure 7: Variation of output torque with speed.

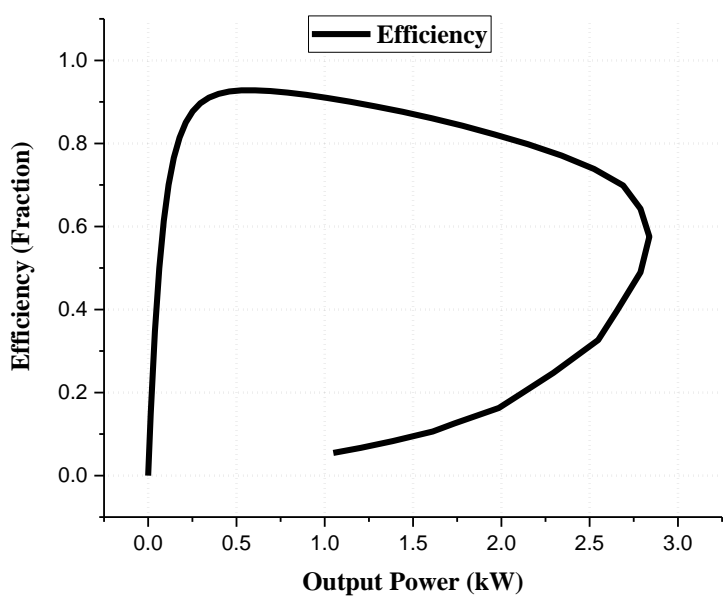

Figure 8: Variation of efficiency with output power. 
Flux-Current curve is shown for different electrical degrees in Figure 11. The flux current diagram is approximately linear as expected. But when rotor of the motor is approaching the excited stator pole, there will be overlapping of the pole corners which indicates the effect of saturation for high level current. The equivalent maximum flux linkage is $1.75 \mathrm{~Wb}$ when the current is $150.5 \mathrm{~A}$ (Figure 9). The flux linkages and maximum phase current with electrical degree are $0.45 \mathrm{~Wb}$ and 146.7A respectively as observed in Figures 10 and 11 respectively. This will be a guide in the choice of stator winding insulation.

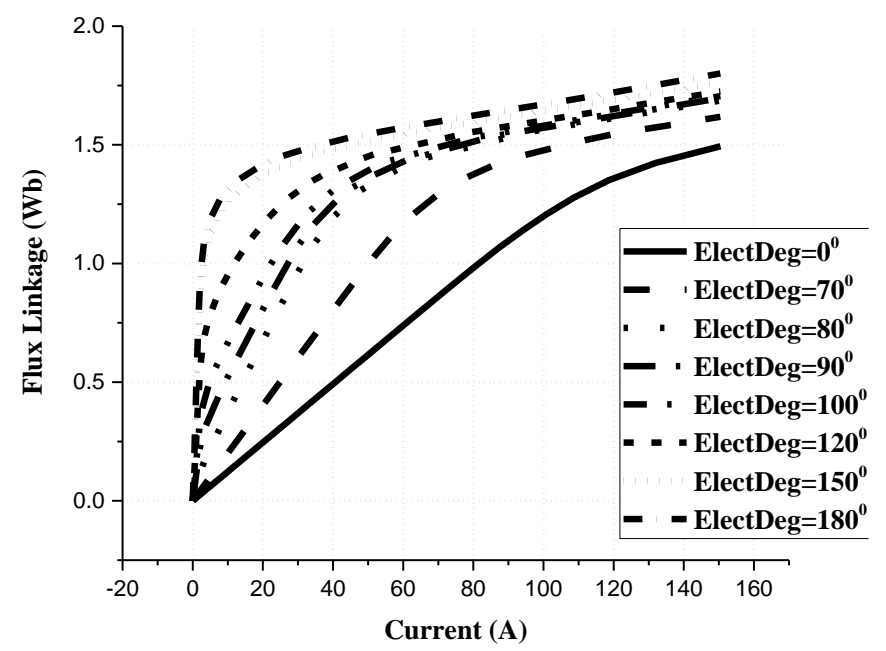

Figure 9: Variation of flux linkage-current relationship.

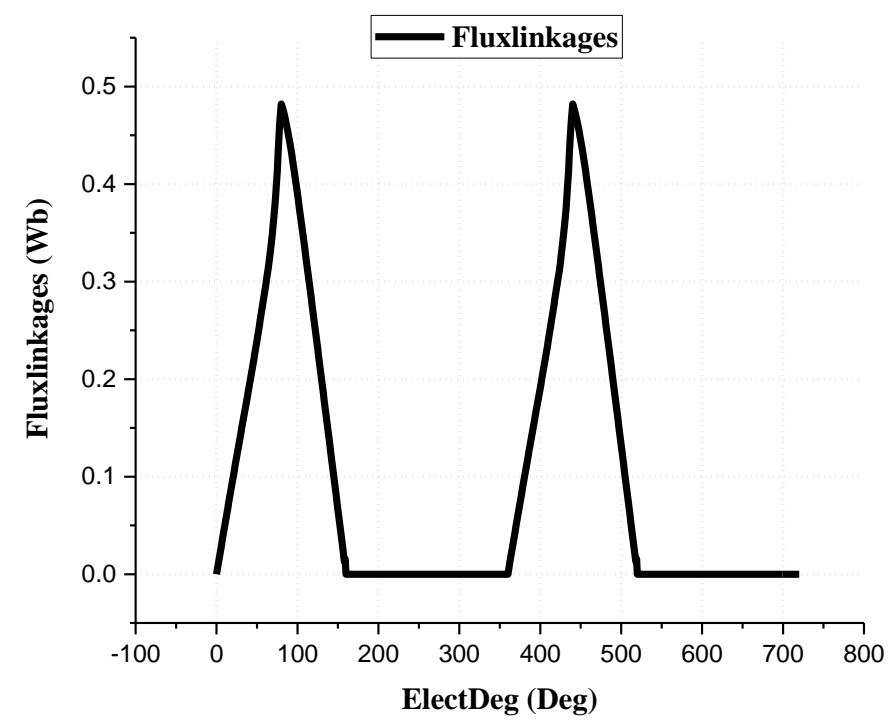

Figure 10: Variation of flux linkage with electrical degree.

\section{B. Transient Analysis Results}

Figures 12 and 13 show the magnetic flux lines and flux density respectively at stop time of $20 \mathrm{~ms}$, speed of 1501.06 $\mathrm{rpm}$ and the rotor position of 195.24 degrees. The results show that the magnetic field is confined within the motor. The external contour of the stator periphery is treated as a line of zero vector potential and most of the field energy is concentrated in the air gap region. The magnetization characteristics of the motor are single valued and the iron regions are isotropic. The maximum and minimum magnetic flux lines of the motor as observed in Figure 12 are 1.22 $\times 10^{-}$ ${ }^{3} \mathrm{~Wb} / \mathrm{m}$ and $-8.52 \times 10^{-4} \mathrm{~Wb} / \mathrm{m}$ respectively.

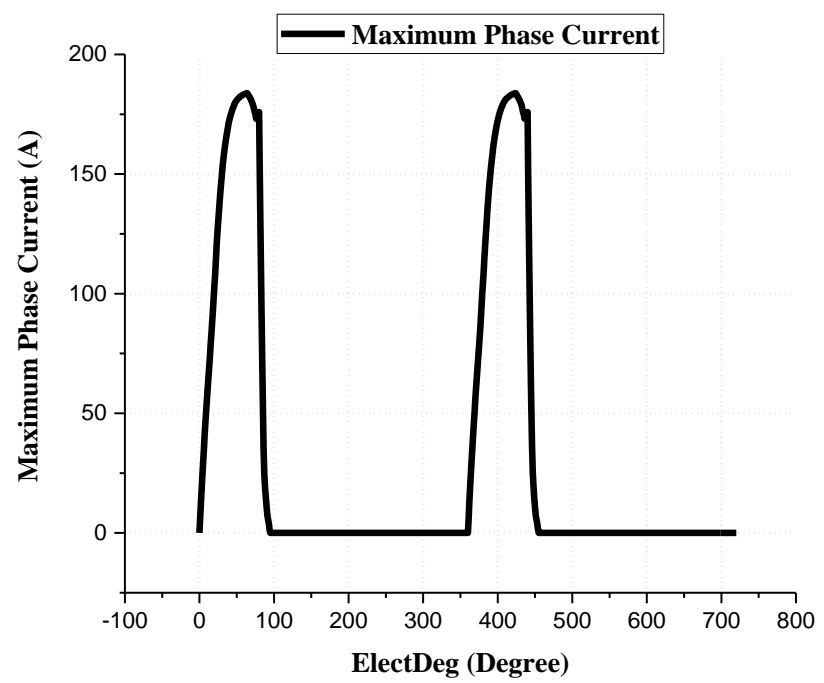

Figure 11: Variation of maximum phase current with electrical degree.

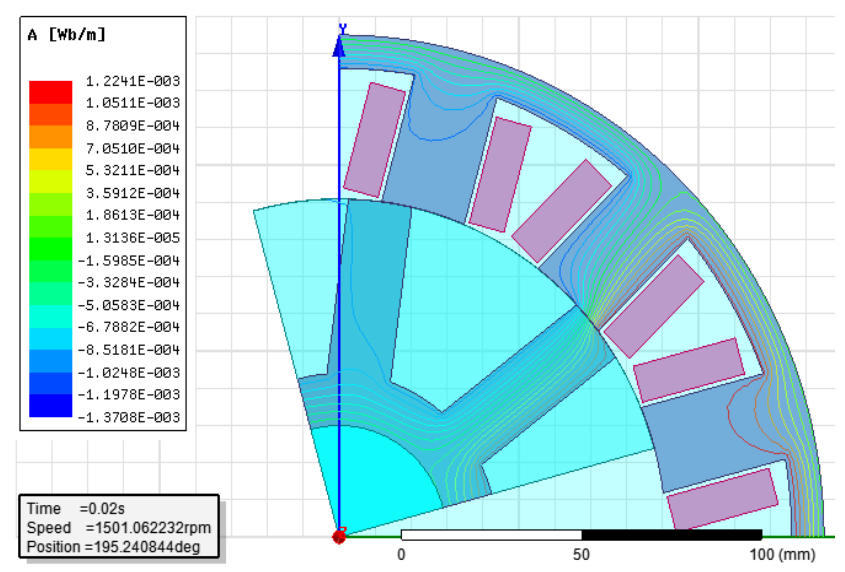

Figure 12: Flux lines pattern for the motor.

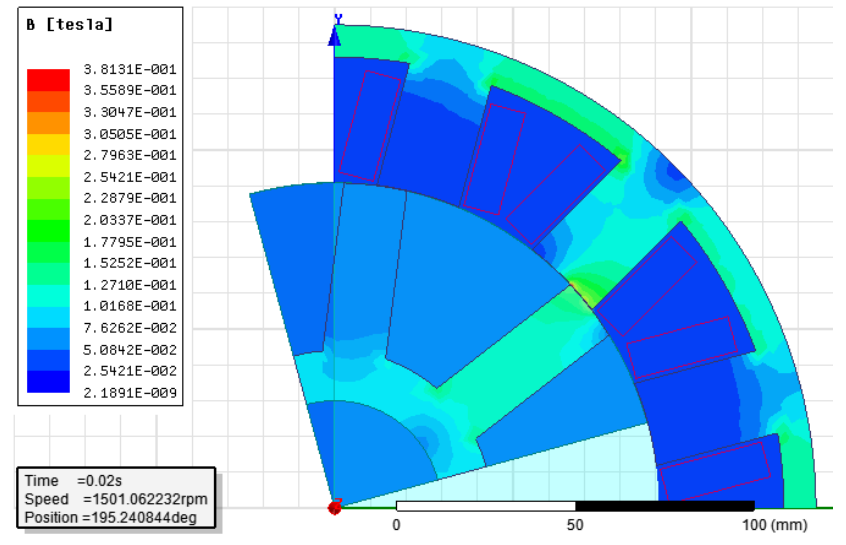

Figure 13: Flux density pattern for the motor. 
From Figure 13, it can be seen that the respective values of the maximum and minimum magnetic flux density of the motor are $3.81 \times 10^{-1} \mathrm{~T}$ and $2.19 \times 10^{-9} \mathrm{~T}$.

To verify the dynamic performance of SRM during operation, the motor was operated on no load. The behavior of the motor was monitored for $0.02 \mathrm{~s}$ at a damping coefficient of $0.71 \mu \mathrm{Nms} / \mathrm{rad}$. Speed and electromagnetic torque have been recorded as well as current and flux linkage as seen in Figures $14-17$.

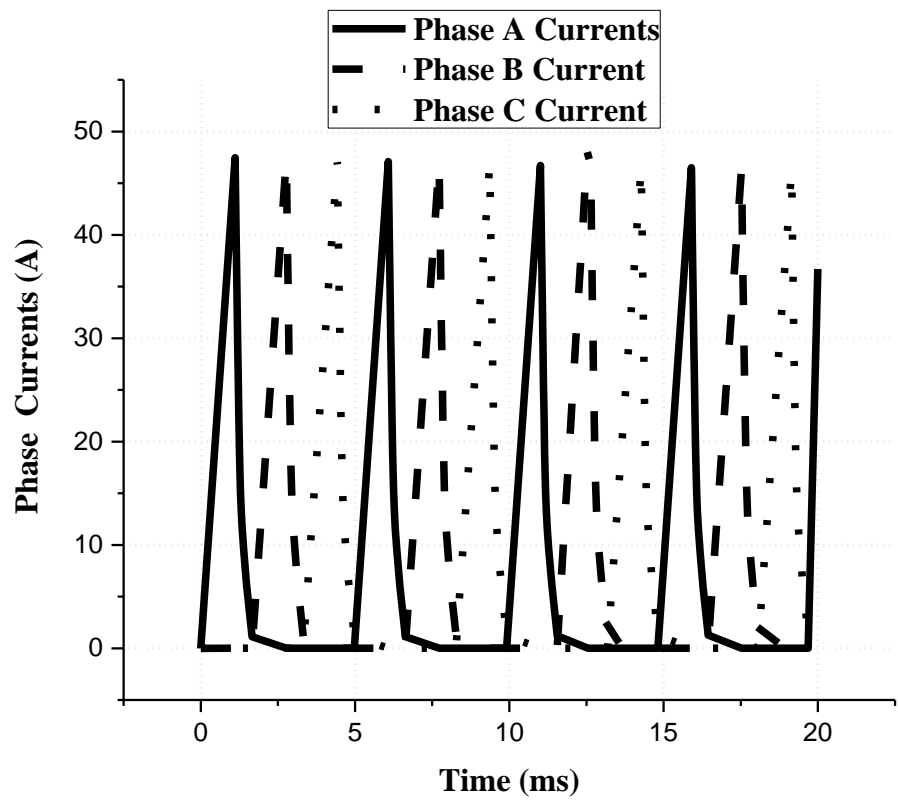

Figure 14: Variation of motor phase current with time.

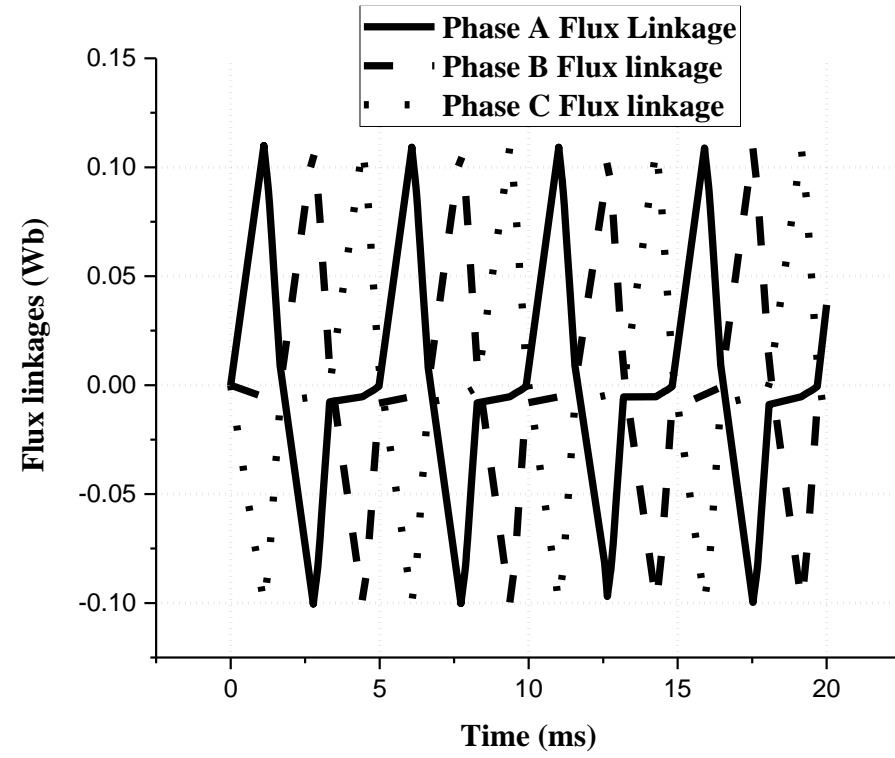

From these results, it can be seen that maximum torque, phase current and flux linkages are $63.8 \mathrm{Nm}, 46.2 \mathrm{~A}$ and $0.11 \mathrm{~Wb}$ respectively. The torque response of Figure 15 shows that the designed motor has a good starting and minimal torque ripple.

Figure 15: Variation of flux linkage with time. 


\section{CONCLUSION}

In this paper, a detailed modeling and simulation of 3-phase 12/8 SRM was performed. The modified inner diameters of both the stator and rotor were $180 \mathrm{~mm}$ and $60 \mathrm{~mm}$ respectively. The basic characteristics of the motor were obtained which shows that the designed motor can be used in high speed operation.

It was observed that the respective values of the maximum and minimum magnetic flux density of the motor were $3.8131 \times 10^{-1} \mathrm{~T}$ and $2.1891 \times 10^{-9} \mathrm{~T}$ respectively. The results of the magnetic flux lines and density showed that most of the field energy are confined within the motor. The results of the transient analysis showed that the motor has improved starting torque and reduced torque ripple. It should be recommended that the starting torque can also be improved by modifying the control and switching circuit of 12/8 SRM.

\section{REFERENCES}

Ahmad, T. (2017). Design and Analysis of a Switched Reluctance Machine for Traction in a Hybrid Automotive Application. Erasmus Mundus Master Course in Sustainable Transportation and Electrical Power Systems, Universidad De Oviedo.

\section{ANSYS Electromagnetics 2018, ANSYS Inc.}

Hams, M.R.; J.W.Finch; J.A. Mallick and T.J.E. Miller. (2004). A Review of the Integral Horsepower Switched Reluctance Drive. IEEE Trans. Ind. Appl. Soc., 56 (22): 33-49.

Jisha, K.; P. Abhijith; J. Mathew; B. Ramesh; M.V. Swathy and J.A. Varun. (2015).Simulation and Magnetic Analysis of Switched Reluctance Motor with Various Rotor Pole Shapes Using Finite Element Method. International Journal of Advanced Research in Electrical, Electronics and Instrumentation Engineering, 4(4): 2398- 2403.

Kakilli, A. (2011). Magnetic Analysis of Modified-Rotor Switched Reluctance Motor. Electronics and Electrical Engineering, 9(115): 21-26.

Krishnan, R. (2001). Switched reluctance motor drivesmodeling, simulation, analysis, design, and applications. CRC Press, Boca Raton, London.

Mecrow, B.C.; J.W. Finch; E.A. EI-Kharashi and A.G. Jack. (2002). The Design of switched reluctance motors with segmental rotors. IEE Proc. of Electr. Power Applications, 149(4): 245-254, 2002.
Miller, T. J. (2001). Electronic Control of switched reluctance machines. Newnes, 225 Wildwood Avenue, Woburn.

Nirdesh, N. (2018).Comparison of Switched Reluctance Motor and Double Stator Switched Reluctance Motor. Thesis, University of New Orleans.

Oyama, J.; T. Higuchi; T. Abe and N. Kifuji. (2004). Switched reluctance motor with Segmented core embedded in Aluminum rotor. Proc of Japan Industry Applications society Conference, 3(1): 493-496.

Oyama, J.; T. Higuchi; T. Abe and N. Kifuji. (2005). Fundamental Characteristics of a novel switched reluctance motor with segmented core embedded in Aluminum rotor. Papers of technical meeting on rotating machinery, IEE Japan, 5(64):43-48.

Piotr B.; K. Mariusz and P. Jan. (2006). Four-Quadrant Operation of Switched Reluctance Machine. Proceedings of Electrotechnical Institute, 6 (229):21-34.

Sagar S. S.; R. M. Sondagar and T. H. Panchal. (2014). Computer Aided Design and Analysis of Switched Reluctance Motor. IEEE Conference on Industrial Electronics and Applications, 7 (9): 953-960.

Simone, S. (2016). Simulation and analysis of Switched Reluctance Generator for renewable energy applications. Thesis, Dublin Institute of Technology, Dublin.

Son-in, S.; T. Kulwora and P. Paolaor. (2019). Magnetic field comparison of $6 / 4$ and $8 / 6$ switched reluctance motor by using the 3-D finite element method. International Journal of Smart Grid and Clean Energy, 1(1): 33-43.

Vijay, G. and Somlal, J. (2012). Design, Modeling and Simulation of 6/4 Switched Reluctance Motor. International Journal of Advanced Scientific Research and Technology, 2(2): 425-432.

Wang, N. and Feng, H. (2018). Research on Torque Ripple and its Minimization Method of Switched Reluctance Motor. 5th International Conference on Information, Cybernetics, and Computational Social Systems (ICCSS), Hangzhou, 2018; 413-417.

Yusuf, O. (2010). Implementation of Dynamic Analysis of SRMwith Modified Pole Geometry, Journal of Electrical/Electronics Engineering, 10 (1): 1197-1200. 